\title{
EMERGENCE OF CORNEA GUTTATA IN DONOR TISSUE: A CAUSE OF LATE GRAFT FAILURE
}

\author{
VIKI CHRISTOPOULOS and ALEC GARNER \\ London
}

\begin{abstract}
SUMMARY
Analysis of $\mathbf{3 2 1}$ failed full-thickness corneal transplant specimens submitted for histopathological examination over a 10 -year period has identified 10 instances in which the defect appeared to have been caused by the development of cornea guttata in the donor tissue. The primary condition necessitating keratoplasty in 5 of the 10 patients was Fuchs' endothelial dystrophy but, given the limited capacity of corneal endothelium for regeneration, it is considered unlikely that the defect in the grafts represented a recurrence. In 7 of 8 cases for which the duration of graft survival was known the endothelial disorder presented as a long-term event and it is assumed that the condition was not present at the time of the keratoplasty. The rare emergence of Fuchs' dystrophy in donor transplant tissue should be added to the potential causes of late graft failure.
\end{abstract}

Failure of a technically correct corneal transplant occurring beyond the period normally associated with immunological rejection can be caused by recurrence of the initial host disease or deficiency of the donor endothelium. Frequently the latter reflects age-related attenuation in donor tissue with an already low endothelial cell population at the time of transplantation, aggravated perhaps by trauma incurred during the surgical procedure. One large reported series of penetrating keratoplasty results indicated that over a third of 1452 repeat grafts were in respect of late endothelial cell decompensation. ${ }^{1}$ Transplants with an endothelial cell count of 400 per square millimetre or less can ultimately be expected to decompensate, ${ }^{2}$ especially where there is spreading of donor cells to compensate for loss of damaged cells. ${ }^{3-5}$ Rarely, however, it seems that endothelial cell dysfunction and loss can be due to an intrinsic abnormality within the donor material and the object of the present paper is to describe 10 cases in which graft failure was associated with the emergence of cornea guttata typical of Fuchs' endothelial dystrophy.

\section{MATERIALS AND METHODS}

During the 10-year period 1983-1992 some 10 cases of

Correspondence to: Professor Alec Garner, Department of Pathology, Institute of Ophthalmology, Bath Street, London EC1V 9EL, UK. corneal graft failure attributable to endothelial cell loss in the presence of guttate excrescences were seen in the Department of Pathology at the Institute of Ophthalmology. Histological sections of the resected full-thickness donor corneas stained with haematoxylin and eosin and by the periodic acid-Schiff method were available for review. The patients' clinical records were available for review in 5 of the cases.

\section{RESULTS}

The underlying conditions necessitating the initial keratoplasties were Fuchs' endothelial dystrophy in 5 cases, keratoconus in 2, and 1 each of macular dystrophy, perforating ulcer and post-trachomatous scarring.

Information concerning the donor material was incomplete but in 8 cases the interval between the initial and repeat keratoplasties varied between 5 weeks and 17 years with a mean of 6.76 years. These and other clinical data are summarised in Table I.

The presence of multiple guttae in positions other than the extreme periphery was confirmed in each of the 10 corneae and seen to be linked with severe endothelial cell atrophy and loss (Fig. 1). The extent to which the stroma was oedematous was difficult to estimate because of the impossibility of calculating the degree of thickening due to artefactual fibre separation. In all instances there was, however, substantial epithelial cell oedema, while in 2 cases there was subepithelial fibrosis. Guttae were not identified in a small amount of recipient tissue accompanying the failed transplant specimen in a single patient grafted for keratoconus. Guttae had been noted clinically in 2 of 5 patients for whom details were available.

Details pertaining to the donor tissue are sparse but in the 5 instances where the age of the donor was known this ranged between 68 and 79 years and the 3 donors for whom the sex was stated were all female.

\section{DISCUSSION}

The finding of 10 cases of cornea guttata consistent with Fuchs' dystrophy is in the context of 321 corneal discs removed for graft failure due to all causes over the same 


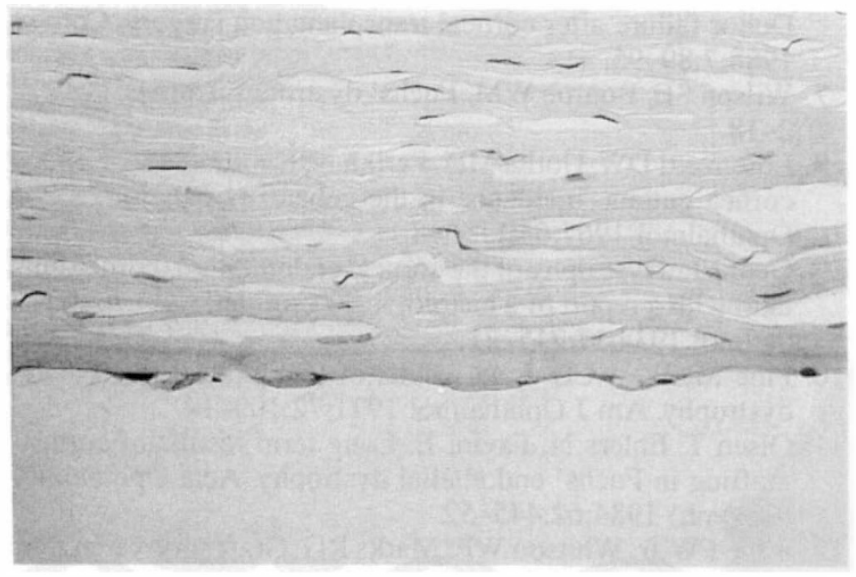

Fig. 1. Case 5. Posterior surface of failed corneal transplant in a patient originally grafted for macular dystrophy. (Haematoxylin and eosin, $\times 190$ ).

10-year period. This incidence (3.12\%) would almost certainly be higher if the unknown proportion of short-term failures were excluded, although it is to be noted that the transplant in 1 patient (case 6) survived for only 5 weeks. The donor in that instance was a 79-year-old woman dying from a cerebrovascular accident but not recorded as having clinically significant visual disturbance. Allowing for that single case, it appears that the interval between graft and regraft is measured in years (range 1.25-17.00 years, mean 7.71 years) and that the emergence of a Fuchs type of disturbance is essentially a cause of late graft failure. It is noteworthy, however, that Buxton and others ${ }^{6}$ reported 5 instances of graft failure within 24 hours of transplantation attributable to Fuchs' dystrophy out of a total 17 donor failures in the course of 1351 procedures. Nevertheless, examination of the donor cornea prior to transplantation will usually exclude material with overt guttae. It seems likely, therefore, that Fuchs' dystrophy presenting at a later date will be potential rather than manifest at the time of surgery, especially as the progression even from the first emergence of guttae to clinically significant oedema can take many years. ${ }^{7}$ That being the case there is currently probably little that can be done to prevent the problem, although it may be noted that, from the limited information provided by the present study, elderly donors incur the greatest risk. In due course, in the event that a gene defect is demonstrated and mapped, it may be possible to screen potential donor material using specific DNA probes.

Understandably, in view of the gender ratio relating to Fuchs' dystrophy, the risk is also likely to be greater in respect of female donors. One estimate of the incidence of central cornea guttata in the general population was that $70 \%$ of people over the age of 50 are affected, although in the vast majority $(96.4 \%)$ the degree of involvement is minimal. ${ }^{8}$ Another study gave an $11 \%$ incidence of guttate excrescences, presumed to be other than peripherally situated Hassall-Henle warts, in patients aged over 50 years attending an eye department for various reasons. ${ }^{9}$ If these estimates are correct it suggests that a sizeable proportion of donor transplants carry an incipient, if rarely manifested, risk of eventual endothelial cell dysfunction.

Five of the graft failures attributable to a Fuchs-like endothelial disorder were in patients whose primary condition was Fuchs' dystrophy. Given that the endothelium of adult corneas is generally assumed not to have a capacity for replication, it must be presumed that the sequence is coincidental rather than that there was recurrence of the host disease. Nevertheless, the finding that 5 of a total 242 histologically confirmed Fuchs' dystrophy cases treated by keratoplasty over the same 10 -year period had donor-related renewal of the condition begs comparison with the incidence of cornea guttata in failed grafts in patients with other primary disorders. Between 1983 and 1992 some 320 keratoconus specimens were received in the laboratory and of these 2 transplants failed because of cornea guttata. Thus the incidence of cornea guttata as a cause of graft failure in the two primary disorders was $2.07 \%$ and $0.62 \%$ respectively (ratio $3.34: 1$ ). The difference is not significant, however, at the $5 \%$ level. Fine and West $^{10}$ in an analysis of 193 penetrating keratoplasties in Fuchs' dystrophy patients followed for up to 15 years described 29 failures but in no instance did this appear to represent recurrence of the primary disorder. Olsen and colleagues ${ }^{11}$ in their study of 33 grafts in patients with this condition described a $12 \%$ long-term failure rate which they attributed to gradually increasing oedema but, although they considered that recurrent primary disease might be responsible, they were not able to confirm it. One of the 3 failed transplants in 241 patients grafted for Fuchs' dystrophy was ascribed to endothelial cell failure in a series reported by Price and others. ${ }^{12}$ If there is an

Table I. Summary of clinical data

\begin{tabular}{|c|c|c|c|c|c|c|c|c|}
\hline \multirow[b]{2}{*}{ Case } & \multicolumn{3}{|c|}{ Recipient } & \multicolumn{3}{|c|}{ Donor } & \multicolumn{2}{|c|}{ Identification of guttae } \\
\hline & Sex & $\operatorname{Age}^{a}(y r)$ & Initial disorder & Sex & Age $(y r)$ & Duration of graft (yr) & Clinical & Histological \\
\hline 1 & $\mathrm{~F}$ & 68 & Fuchs’dystrophy & & & 4.50 & - & + \\
\hline 2 & M & 78 & Fuchs' dystrophy & & & & & + \\
\hline 3 & $\mathrm{~F}$ & 70 & Fuchs' dystrophy & & & & & + \\
\hline 4 & $\mathrm{~F}$ & 67 & Fuchs'dystrophy & & & 5.00 & & + \\
\hline 5 & M & 22 & Macular dystrophy & $\mathrm{F}$ & 69 & 1.25 & - & + \\
\hline 6 & M & 75 & Trachoma & $\mathrm{F}$ & 79 & 0.10 . & & + \\
\hline 7 & $\mathrm{~F}$ & 33 & Keratitis & & 68 & 17.00 & - & + \\
\hline 8 & $\mathrm{~F}$ & 66 & Fuchs' dystrophy & & 72 & 8.25 & + & + \\
\hline 9 & $\mathrm{~F}$ & 41 & Keratoconus & $\mathrm{F}$ & 69 & 5.00 & - & + \\
\hline 10 & M & 21 & Keratoconus & & & 15.00 & + & + \\
\hline
\end{tabular}

${ }^{\mathrm{a} A g e}$ at time of penetrating keratoplasty. 
increased risk that the primary condition will recur in patients treated for Fuchs' dystrophy there are two possibilities: either factors in the host environment encourage expression of the donor tissue potential or, contrary to the general opinion, ${ }^{13,14}$ some repopulation of the graft by host endothelium occurs. The latter might represent spreading of existing cells to replace areas of damaged donor endothelium and does not have to involve cell division.

Key words: Fuchs' dystrophy, Graft failure, Penetrating keratoplasty.

\section{REFERENCES}

1. Sharif KW, Casey TA. Changing indications for penetrating keratoplasty, 1971-1990. Eye 1993;7:485-8.

2. Casey TA, Mayer DJ. Corneal grafting: principles and practice. Saunders: Philadelphia, 1984:264.

3. Bron AJ, Brown NAP. Endothelium of the corneal graft. Trans Ophthalmol Soc UK 1974;94:863-73.

4. Kaufman HE, Katz JI. Endothelial damage from intraocular lens insertion. Invest Ophthalmol 1976;15:996-1000.

5. Mishima S. Clinical investigations on the corneal endothelium. Am J Ophthalmol 1982;93:1-29.

6. Buxton JN, Seedor JA, Perry HD, Eagle RC, Pecego JA.
Donor failure after corneal transplantation surgery. Cornea 1988;7:89-95.

7. Wilson SE, Bourne WM. Fuchs' dystrophy. Cornea 1988;7: 2-18.

8. Lorenzetti DW, Uotila MH, Parikh N, Kaufman HE. Central cornea guttata: incidence in the general population. Am J Ophthalmol 1967;64:1155-8.

9. Goar EL. Dystrophy of the corneal endothelium (cornea guttata) with a report of a histological examination. Am J Ophthalmol 1934;17:215-21.

10. Fine M, West CE. Late results of keratoplasty for Fuchs' dystrophy. Am J Ophthalmol 1971;72:109-14.

11. Olsen T, Ehlers N, Favini E. Long term results of corneal grafting in Fuchs' endothelial dystrophy. Acta Ophthalmol (Copenh) 1984;62:445-52.

12. Price FW Jr, Whitson WE, Marks RG. Graft survival in four common groups of patients undergoing penetrating keratoplasty. Ophthalmology 1991;98:322-8.

13. Laing RA, Sandstrom MM, Beropsi AR, Leibovitz HM. Morphological changes in corneal endothelial cells after penetrating keratoplasty. Am J Ophthalmol 1976;82: 459-64.

14. Rao GN, Aquavella JV. Peripheral recipient endothelium following corneal transplantation. Ophthalmology 1981;88: 50-5. 